\title{
RESOLVING THE GLOBAL SURFACE SALINITY FIELD AND VARIATIONS BY BLENDING SATELLITE AND IN SITU OBSERVATIONS
}

\author{
Gary Lagerloef $^{(1)}$, Jacqueline Boutin ${ }^{(2)}$, Yi Chao ${ }^{(3)}$, Thierry Delcroix ${ }^{(4)}$, Jordi Font ${ }^{(5)}$, Peter Niiler ${ }^{(6)}$, Nicolas \\ Reul $^{(7)}$, Steve Riser ${ }^{(8)}$, Ray Schmitt ${ }^{(9)}$, Detlef Stammer ${ }^{(10)}$, Frank Wentz ${ }^{(11)}$ \\ ${ }^{(1)}$ Earth and Space Research, 2101 4th Ave, Suite 1310989121 Seattle USA, \\ Email: lager@esr.org \\ (2) LOCEAN (Laboratoire d'Océanographie: Expérimentation et Approches Numériques), University of Paris, \\ 4, Place Jussieu, 75252 Paris Cedex 05, France, \\ Email: jb@locean-ipsl.upmc.fr \\ ${ }^{(3)}$ NASA (National Aeronautics and Space Administration) Jet Propulsion Laboratory, \\ 4800 Oak Grove Dr, Pasadena, California 91109 USA, Email: Yi.Chao@jpl.nasa.gov \\ (4) LEGOS (Laboratoire d'Études en Géophysique et Océanographie Spatiales), 14 Avenue Edouard Belin - 31401 \\ Toulouse Cedex 9, France, Email: Thierry.Delcroix@legos.obs-mip.fr \\ ${ }^{(5)}$ Inst. Ciencias de la Mar, Passeig Marítim de la Barceloneta, 37-49. E-08003 Barcelona Spain, \\ Email:jfont@icm.csic.es \\ (6) Scripps Institution of Oceanography, 9500 Gilman Drive, La Jolla, CA 92093-0238, USA, \\ Email: pniiler@ucsd.edu \\ (7) CERSAT/IFREMER (Centre ERS (Earth \& Space Research) d'Archivage et de Traitement/French Institute for \\ Exploitation of the Sea/Institut Français de Recherche pour l'Exploitation de la Mer), \\ 155, rue Jean-Jacques Rousseau - 92138 Issy-les-Moulineaux Cedex, France, \\ Email: Nicolas.Reul@ifremer.fr \\ ${ }^{(8)}$ University of Washington, 1013 NE 40th St, Seattle, WA 98105-66985, USA, \\ Email: riser@ocean.washington.edu \\ ${ }^{(9)}$ Woods Hole Oceanographic Inst., MS 11, Woods Hole, MA 02543 USA, \\ Email: rschmitt@whoi.edu \\ ${ }^{(10)}$ Institut fuer Meereskunde, Universität Hamburg, Bundesstrasse 53, D-20146 Hamburg Germany, \\ Email: detlef.stammer@zmaw.de \\ ${ }^{(11)}$ Remote Sensing Systems, 438 First St., Santa Rosa, CA 95401 USA, \\ Email:frank.wentz@remss.com
}

\begin{abstract}
This Community White Paper (CWP) examines the present Sea Surface Salinity (SSS) observing system, satellite systems to measure SSS and the requirements for satellite calibration and data validation. We provide recommendations for augmenting the in situ observing network to improve the synergism between in situ and remote sensing measurements. The goal is have an integrated (in situ-satellite) salinity observing system to provide necessary the global salinity analyses to open new frontiers of ocean and climate research. It is now well established that SSS is one of the fundamental variables for which sustained global observations are required to improve our knowledge and prediction of the ocean circulation, global water cycle and climate. With the advent of two new satellites, the ocean observing system will begin a new era for measuring and understanding the SSS field. The SMOS (Soil Moisture and Ocean Salinity) and Aquarius/SAC-D (Scientific Application Satellite-D) missions planned to be launched between late 2009 and late 2010, are intended to provide $\sim 150-200 \mathrm{~km}$ spatial resolution globally, and accuracy $\sim 0.2 \mathrm{psu}$, or better, on monthly average. The challenge for the next decade is to combine these satellite and in situ systems to generate
\end{abstract}

the optimal global SSS analysis for climate and ocean research. The in situ data provide surface calibration and validation for the satellite data, while the satellites provide more complete spatial and temporal coverage. The first priority is the maintenance of the existing in situ SSS observing network. In addition, we propose specific enhancements, ideally to include (1) deploying $\sim 200$ SSS sensors on surface velocity drifters and moorings in key regions, and (2) adding higher vertical resolution near-surface profiles to $\sim 100$ Argo buoys to address surface stratification, mixing and skin effects. Plans during the next few years to deploy a significant fraction of these enhanced measurements are identified.

\section{INTRODUCTION}

The scientific relevance for measuring SSS is becoming broadly recognized [1]. Salinity is known to play an important role in the dynamics of the thermohaline overturning circulation, ENSO (El Niño/Southern Oscillation), and is the key tracer for the marine branch of the global hydrologic cycle, which comprises about $3 / 4$ of the global precipitation and evaporation. Multidecadal trends SSS trends have been documented in tropical [2] and northern latitudes [3] that are likely signatures of evaporation or precipitation trends, as 


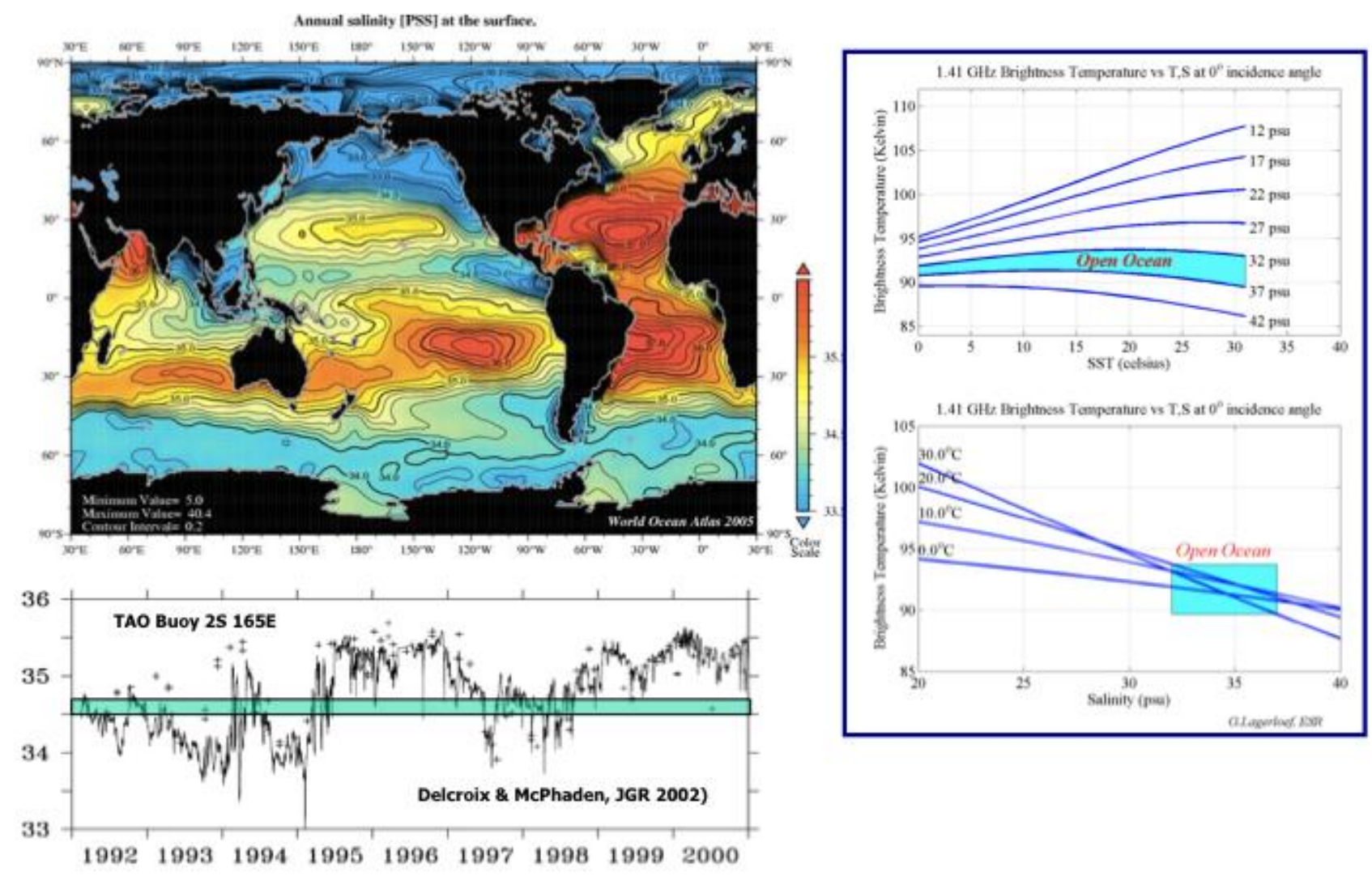

Figure 1: Upper left: The mean annual sea surface salinity (SSS) from the World Ocean Atlas 2005 (Boyer et al, 2006). The open ocean dynamic range is about 5 psu. Lower left: A multi-year SSS time series from a mooring in the western equatorial Pacific. The width of the center line shows that a monthly average measurement uncertainty of 0.2 pss will resolve the seasonal to interannual variability. Upper right: The $1.413 \mathrm{GHz}$ radiometric brightness temperature $\left(T_{B}\right)$ as a function of sea surface temperature (SST) for various salinities, with the open ocean salinity range shaded. Salinity is retrieved from independent measurements of $T_{B}$ and SST. Lower right: $T_{B}$ as a function of salinity for various temperatures, showing that radiometric sensitivity (line slope), hence retrieval accuracy, is greater in warmer water. On average, 0.2 pss uncertainty requires that $T_{B}$ is measured to $0.1 \mathrm{~K}$ accuracy, requiring very precise radiometric measurement.

predicted under global warming scenarios. SSS is also essential to understanding the ocean's interior water masses, knowing that they derive their underlying T\&S (Temperature \& Salinity) properties during their most recent surface interval.

Our basic knowledge about the global SSS distribution is derived from the World Ocean Atlas 2005 (WOA05), a careful compilation of all the available oceanographic data collected over time [4] and [5]. The mean annual climatology shows the salient basin scale features, such as the elevated SSS in the Atlantic relative to the other basins, and the general correspondence of lower SSS with climatologically high precipitation zones and vice versa. In the open ocean, apart from marginal seas, coastlines and major rivers, the SSS dynamic range varies from a minimum of $\sim 32$ in the northeast Pacific to a maximum of $\sim 37$ in the subtropical North Atlantic, for a range of about 5 pss. The SSS sampling distribution in WOA05 remains sparse and irregular, especially in the southern hemisphere, so that large spatial smoothing scales $(\sim 800-1000 \mathrm{~km})$ are needed to generate such climatological SSS maps. What is lacking from the historical data set is the systematic spatial and temporal sampling resolution to document the synoptic seasonal to interannual SSS variability and its relationship to relevant ocean and atmospheric processes. Ideally, a global 'snapshot' like the map in Fig. 1, with better spatial resolution, is needed on monthly time scales to reveal these interactions. 

During OceanObs'99, [6] described a SSS regional case study for the tropical Pacific to guide the design of surface salinity satellite and in situ observing networks. They estimated from spatial and temporal decorrelation scales that $100 \mathrm{~km}$ and monthly resolution and $0.1 \mathrm{pss}$ error would be sufficient to resolve the climatologically important seasonal to interannual signals. They also found that sample errors from sparse in situ measurements are on the order of $0.1-0.2$ pss given the observed space-time variability. These results helped guide measurement requirements for both in situ and satellite observing systems.

The SSS observing system has expanded significantly during the decade since the OceanObs'99. The most quantitative increase has come about with the full deployment of the Argo array in recent years with $>3000$ floats providing an average of one sample every $300-400 \mathrm{~km}$ square every 10 days. Already, these data are useful for documenting the changes in the large scale salinity field in recent years [7] and [8]. The tropical mooring arrays (TAO, PIRATA, RAMA (Tropical Atmosphere Ocean, Pilot Research Moored Array in the Tropical Atlantic, Moored Array for African-Asian-Australian Monsoon Analysis and Prediction)) are almost completely outfitted with SSS sensors. Figure 1 provides an extended time series from one such pilot mooring in the western equatorial Pacific, which shows that the 0.2 pss retrieval accuracy will resolve the seasonal to interannual SSS variability in this region. The underway ship thermosalinograph measurement program has continued, and as shown below, the data provide quantitative information about SSS spatial variability to understand the uncertainties in matching in situ observations with satellite data for calibration and validation. Another observing platform with the potential to substantially enhance in SSS observing capability is the surface velocity drifter program, as the technical obstacles for calibration stability are being resolved.

Notwithstanding these gains of the past decade, the in situ sample density remains sparse compared to the sampling capabilities to be achieved by the satellites, which will systematically map SSS over all areas of the open ocean (excluding near land and ice boundaries). In terms of the number of $1 \mathrm{x} 1$ degree boxes with an SSS sample over a specified time (say 10 days), the satellite sampling will outnumber the 3000 floats Argo array by a factor of 10 or so. The absolute accuracy of the satellite SSS measurements will be commensurately less than automated in situ sensors. However, as was shown by [6] and in the discussion below, the error between point measurements and spatio-temporal averages can exceed the retrieval accuracy of the satellite data at the same resolution scales. Accordingly, the satellite and in situ observing systems will complement each other when their respective merits are put to use. The US
CLIVAR Salinity Working Group (SWG) provided several priority recommendations in a brief review [1]. These include 1) Maintain the Argo program, 2) Add surface Argo salinity measurements (upper 5m), 3) Add SSS measurements to the Global Drifter Program (GDP) buoys, 4) Expand TSG (Thermosalinograph) usage on VOS (Volunteer Observing Ship), 5) Maintain/expand moored array salinity sensors, etc. The present OceanObs CWP provides further analysis of the synergy between satellite and in situ SSS measurements and specific recommendations for SSS on Argo and GDP floats, including where they should be deployed, how many, when and estimated new resources required

\section{SATELLITE SYSTEMS}

\subsection{A brief primer on salinity remote sensing}

In the simplest terms, the microwave emission of the sea surface at a given radio frequency depends partly on the dielectric constant of sea water, which in turn is partly related to salinity and temperature [9] and [10]. The strength of the emission (called total power) can be measured remotely with a microwave radiometer. The radiometer output is generally given in terms of a parameter called brightness temperature $\left(T_{B}\right)$, which is the product of the surface emissivity (e) and the absolute temperature of the sea surface $(T): T_{B}=e T$. The emissivity also depends on the viewing angle (from nadir), polarization (horizontal or vertical) and surface roughness [11]. Satellite remote sensing is done at protected band centered at $1.413 \mathrm{GHz}$ to avoid radio interference. Figure 1 shows the relationship between $\mathrm{T}_{\mathrm{B}}$, SST (Sea Survace Temperature) and SSS for vertical polarization at a particular viewing angle. The contour lines are for salinities ranging from 32 to 37 psu. It is easy to see that a unique value of salinity can be retrieved when $T_{B}$ and SST are both known. This is the essence of how salinity remote sensing is achieved, although it is more complicated in practice.

Several external factors affect the brightness temperature seen by the radiometer and must be corrected for. The most formidable is the effect of surface roughness or sea state. This is primarily a function of wind speed, and satellite missions are employing different strategies to make corrections to the data (see below). It is also evident (Fig. 1) that the sensitivity decreases with decreasing SST. Accordingly, the SSS retrieval error will increase in higher latitudes, which is partly offset by averaging the greater number of samples obtained in those latitudes with a polar orbiting satellite.

The sensitivity (change of $\mathrm{T}_{\mathrm{B}}$ per change in SSS) in the open ocean is negligible at frequencies $>5 \mathrm{GHz}$, which is why salinity measurement is generally not feasible with conventional satellite sensors which operate at 
higher microwave frequencies. Very strong salinity gradients in the Amazon plume region have been detected recently using the combination of satellite AMSR (Advanced Microwave Scanning Radiometer) data at 6 and $10 \mathrm{GHz}[12]$. Nevertheless, salinity remote sensing over the entire ocean must be done at lower frequencies in the range of $1-2 \mathrm{GHz}$ to achieve useful sensitivity. This constraint presents unique technical challenges for satellite missions. The microwave radiometers must be designed and built to provide very high accuracy, and the antenna structures must be quite large to provide useful spatial resolution at the surface (if the antenna is too small, the footprint diameter becomes too large).

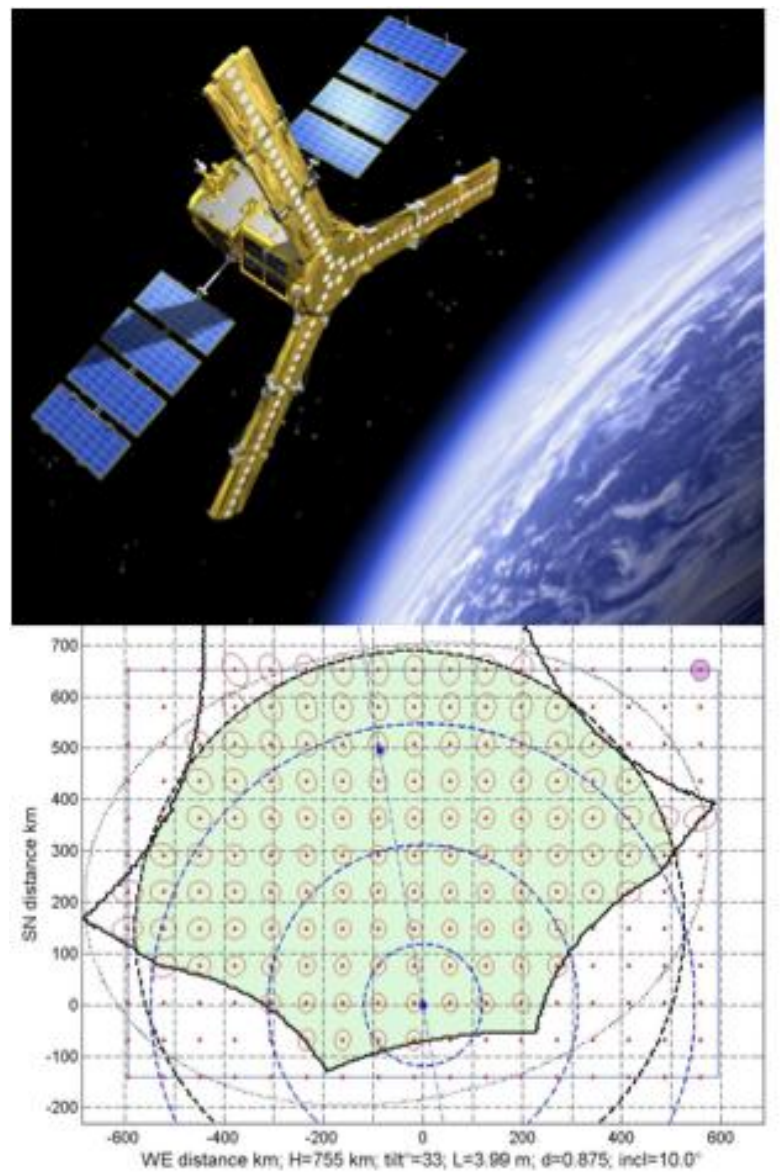

Figure 2: Upper Panel: The European Space Agency Soil Moisture Ocean Salinity (SMOS) mission. The three radial arms contain small microwave (1.413 $\mathrm{GHz}$ ) detectors that form a phased array that is about six meters in diameter. Lower panel: The SMOS field of view covers a swath about $1000 \mathrm{~km}$ wide, with the average pixel size $\sim 43 \mathrm{~km}$. The maximum revisit time is 3 days.

\subsection{Soil Moisture Ocean Salinity (SMOS) Mission}

Developed by the European Space Agency (ESA) in cooperation with the space agencies of France and Spain, the SMOS mission (Fig. 2) was launched in November 2009. As the name implies, SMOS is a dual science mission, with the engineering design driven primarily by acquiring high spatial resolution over land, where the signal strength of surface TB (Brightness Temperature) is much greater than over the ocean. The radiometric signals associated with SSS variability are small relative to the SMOS radiometer sensitivity, and the data will require careful calibration and considerable spatio-temporal averaging to reduce measurement noise [13]. Nevertheless, SMOS will likely be the first satellite to provide exploratory global SSS observations. The release of data to the science validation team (SMOS Validation and Retrieval Team, selected after an ESA call for cal/val proposals in 2005) is expected by four months after launch. For scientific exploitation, the data will be released after the end of the Commissioning Phase, six months after launch. An announcement of opportunity in 2007 resulted in the selection of proposals for SMOS data applications, although other users can also register through the regular ESA Earth Observation data provision system. The SMOS satellite will fly in a near polar sun-synchronous orbit, crossing the equator at 6 am (ascending or northward) and $6 \mathrm{pm}$ (descending or southward) local time. As shown in Fig. 2, the sensor consists of three radial arms with 69 small microwave $(1.413 \mathrm{GHz})$ detectors that form a phased array that is about six meters in diameter. From the inter-correlations and considerable ground processing, a two-dimensional image is reconstructed with the pattern shown in Fig. 2, with an average pixel size of $43 \mathrm{~km}$. The field of view is about $1000 \mathrm{~km}$ wide, and the maximum revisit time interval at the equator is about 3 days.

A surface location is observed multiple times at various angles as the satellite moves along the trajectory. Each viewing angle has different horizontal and vertical polarized surface TB responses to SSS, SST and wind. This information is exploited with a maximum likelihood estimate algorithm to derive SSS, SST and a wind parameter simultaneously [14], [15] and [16]). There is also a parallel effort to develop an alternative algorithm based on neural networks. The retrieval accuracy of these methods remains quite sensitive to initial constraints, radiative transfer model, choice of ancillary data and the range of model functions for wind speed effects. Additional error sources due to instrument biases, image reconstruction processing, and other prominent geophysical correction terms continue to be studied. The actual on-orbit SSS retrieval accuracy is a subject of ongoing refinement of the algorithm, and the retrieval errors per pixel will be reduced by spatiotemporal averaging to $200 \mathrm{~km}$ by 30 day scales. The 
official SMOS ESA mission will deliver data up to level 2 (along swath geo-located retrieved salinity per orbit), with an additional Near Real Time processing chain implemented for operational applications by meteorological centers (mainly for soil moisture). The spatio-temporal averaged and analyzed products (level 3), as well as other value added products including external information (level 4), will be generated and distributed by dedicated processing centers in France and Spain.

\subsection{Aquarius/SAC-D Mission}

Now due to launch in late 2010, the Aquarius/SAC-D mission (Fig. 3) is being developed under a bilateral partnership between NASA (National Aeronautics and Space Administration) and Argentina's space agency (CONAE (National Space Activities Commission)), with supplemental participation by the Italian, French and Canadian space agencies. NASA is providing the Aquarius instrument to measure salinity and CONAE is building the SAC-D satellite and additional science instruments. SSS is the primary scientific measurement goal [17]. The mission design is driven by the requirement to retrieve $\mathrm{SSS}$ at a $150 \mathrm{~km}$ spatial scale, and monthly average root mean square (rms) error less than $0.2 \mathrm{psu}$, including correction for all systematic errors, biases, and geophysical effects. A joint NASACONAE science working team selection will be completed by end of summer 2009 covering studies to prepare the science community to use the SSS data, analyze error sources and provide data validation, as well as exploit additional sensors on the mission that address other science objectives. A subsequent announcement in 2010 will solicit studies to conduct science investigations through the use of Aquarius data.

The mission is designed with key aspects to achieve the required SSS accuracy. The Aquarius instrument includes a set of precisely calibrated $(\sim 0.1 \mathrm{~K})$ satellite microwave radiometers, as well as a radar backscatter sensor to correct for the surface roughness effect [18]. Surface roughness remains the largest uncertainty in the retrieval error budget (see below). The Aquarius/SACD (Scientific Application Satellite-D orbit will be near polar, sun-synchronous, crossing the equator at $6 \mathrm{pm}$ (ascending or northward) and 6 am (descending or southward) local time (opposite times from SMOS). The orbit repeats the ground track every 7 days with 103 revolutions, and the spacing between track lines is 390 $\mathrm{km}$ at the equator. The sensor has three separate radiometers oriented with a $2.5 \mathrm{~m}$ antenna reflector to form a 3-beam swath, ranging from 90 to
$150 \mathrm{~km}$ beam widths as shown on the diagram (Fig. 3). The $390 \mathrm{~km}$ swath width is the same as the cross track spacing to ensure $100 \%$ spatial coverage in a 7 -day period.

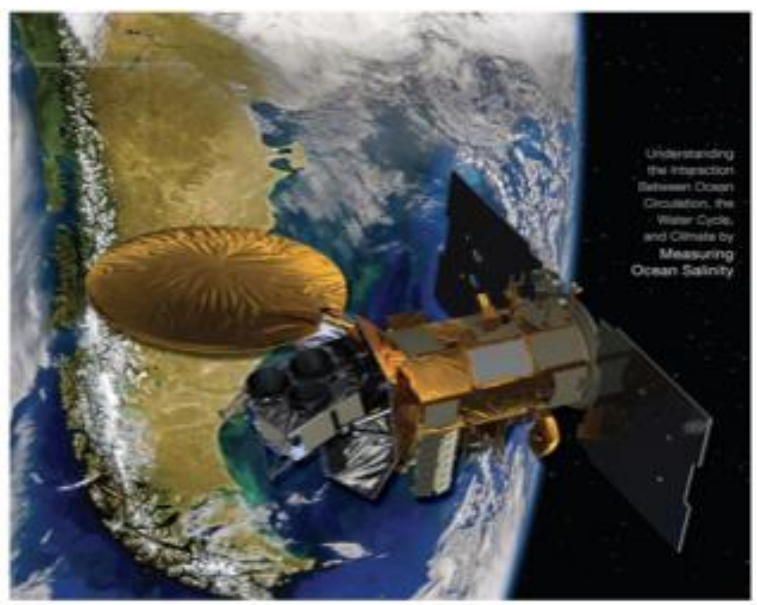

3 beams $390 \mathrm{~km}$ wide swath

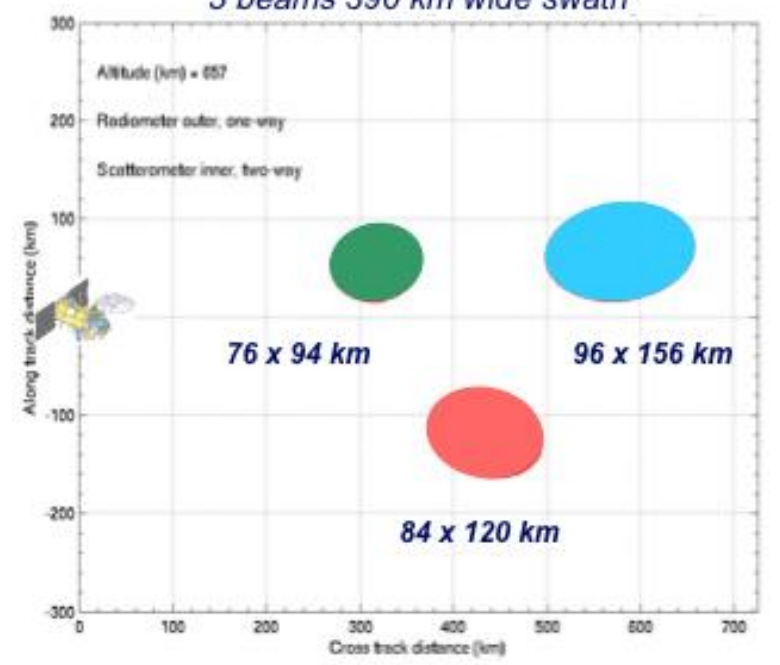

Figure 3: Upper panel: The Aquarius/SAC-D satellite sponsored by NASA and CONAE (the Argentine space agency). The salinity sensor microwave instrument system consists of three separate $1.413 \mathrm{GHz}$ microwave polarimetric radiometers with an integrated $1.2 \mathrm{GHz}$ radar scatterometer, and a $2.5 \mathrm{~m}$ aperture antenna. Lower panel: The three radiometer beams vary between 90 and $150 \mathrm{~km}$ width, depending on look angle, and are arranged in a cross-track swath totaling $390 \mathrm{~km}$. 
The observatory will actually provide two independent maps each week, one each for ascending and descending orbits. Ideally these can be averaged over a month to reduce the measurement noise and satisfy the accuracy requirement. In practice, a more sophisticated objective analysis algorithm will be used to derive a $1 \times 1$ degree grid SSS data field with $150 \mathrm{~km}$ errordecorrelation scale. The science data files that will be provided by the project team include Level 1a (unprocessed raw data), Level $2 \mathrm{~b}$ (swath format science data file, including retrieved SSS calibrated and validated with in situ SSS observing network, calibrated TB, radar backscatter, and all other ancillary geophysical data and corrections), and Level $3 b$ (1x1degree gridded SSS, error covariance and gradient fields objectively analyzed every 7 and every 30 days). . The Aquarius data policy is to release un-validated science data to any user as soon as it is processed (generally $<24$ hours from time of observation), beginning about 45 days after launch. The project is required to release the first six months of validated data within the first 12 months of operations, and the next increment every six months thereafter. In all likelihood, the validated data will be released earlier than required. Higher-level data products such as blended satellite and in situ data fields, blended Aquarius-SMOS analyses and data assimilation products will be addressed by the science teams and the broader science community working in collaboration.

\subsection{Aquarius simulation and errors}

A comprehensive simulator has been developed for analyzing the Aquarius SSS retrieval algorithms and errors [19]. It includes the following steps:

- A time varying global SSS and SST analysis over 30 days from an ocean general circulation model (OGCM) was sampled every 5.76 seconds (Aquarius integration time) according to the on-orbit footprint geometry.

- These were converted to horizontal and vertical polarized $\mathrm{T}_{\mathrm{B}}$ with the emissivity model and estimated emissivity change due to roughness based on the local wind speed.

- A radiative transfer model adjusted $T_{B}$ for propagation through the atmosphere and ionosphere [20] assuming worst-case conditions at the peak of the solar cycle.
- The signal from the earth (land and ocean) as well as radiation from the sky were integrated over the antenna gain pattern to compute the polarized antenna temperatures $\left(\mathrm{T}_{\mathrm{A}}\right)$ actually sensed by the three individual radiometer sensors.

- Measurement noise was added appropriately based on the analyzed uncertainties of the sensor itself, radiative transfer terms and surface winds.

- The retrieval algorithm was used to reconstruct the surface salinity as it would with the actual satellite TA data and compared with the input OGCM data.

The results of the retrieval simulation are shown in Fig. 4. The 30-day mean retrieval SSS accurately portrays the input field. The zonal averages of the mean difference show very small residuals over most latitudes, while systematic errors are apparent at the higher northern latitudes, yet remaining $\leq 0.2 \mathrm{psu}$. In general, the difference standard deviations are smallest in tropical and mid latitudes (warmer SST) and sharply increasing toward the poles (colder SST) as would be predicted from the emissivity model (Fig. 1). The global standard deviation for 5.6 second samples and land fraction $<0.1 \%$ is $\sim 0.15 \mathrm{psu}$ in the latitude range $40 \mathrm{~S}-40 \mathrm{~N}$ (SST>10C) and 0.22 psu for all SSTs. Other errors that are not yet included in the simulation, include galactic reflection, more complex wind/wave response, and surface radio-frequency interference (RFI). Accurate salinity retrievals in the subpolar seas will remain problematical, and this implies that special consideration be given to the future needs for in situ observations in these regions.

\section{SYNERGY BETWEEN SATELLITE AND IN SITU OBSERVING SYSTEMS}

\subsection{Satellite Calibration and data Validation (Cal/Val)}

Matching satellite measurements with in situ surface oceanographic data serves these two functions. Calibration involves tuning the retrieval algorithms as well as adjusting biases and monitoring the calibration drift of satellite sensors. Validation entails a statistical analysis of the residual salinity errors, after the calibration corrections have been applied, to quantify the measurement uncertainty. These analyses proceed by tabulating co-located and coincident satellite and in situ measurements, and taking into account the different sampling characteristics of each. 

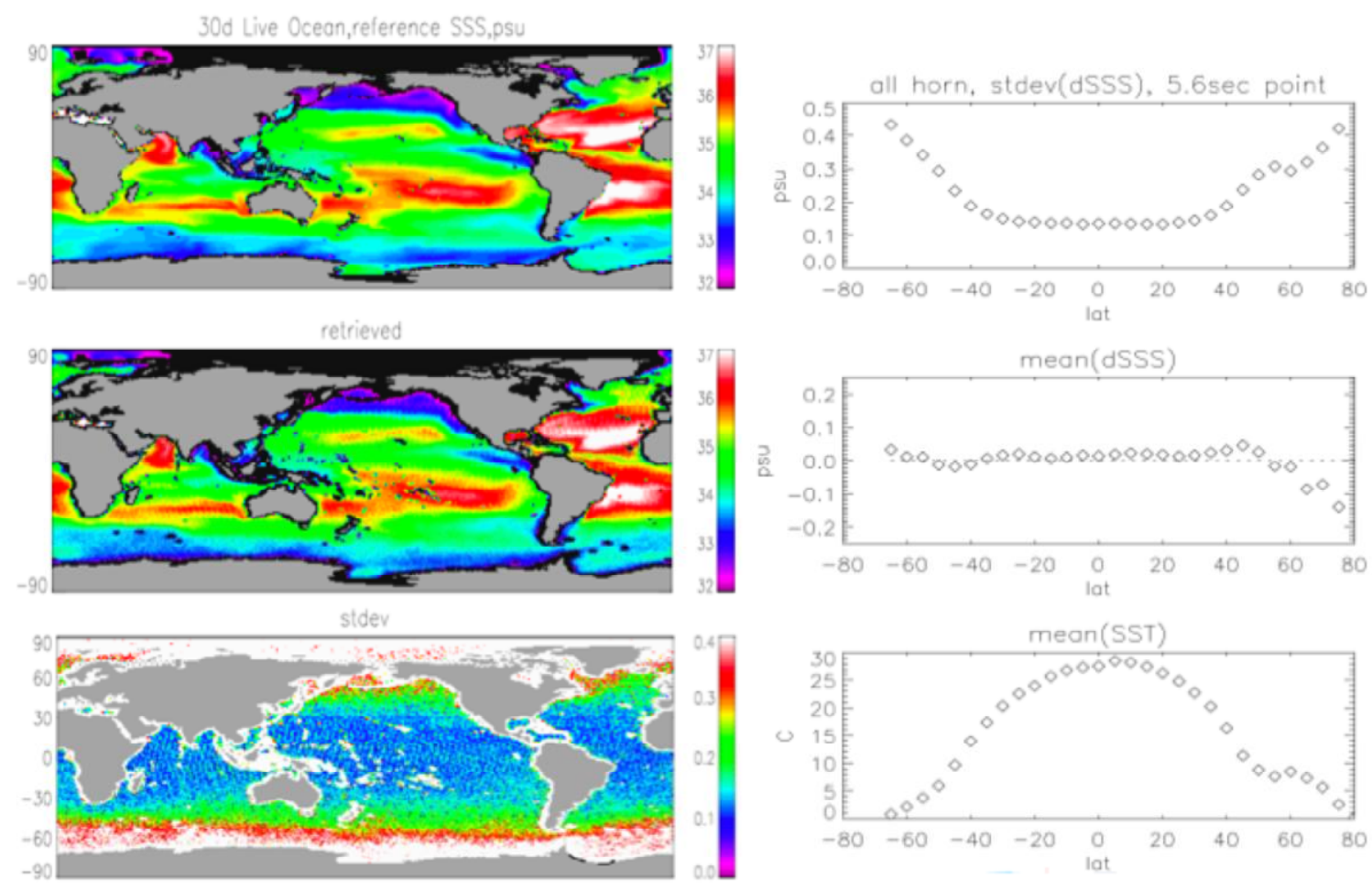

Figure 4: Results of the Aquarius/SAC-D salinity retrieval 30-day simulation described in the text. Left panels show the mean input SSS, simulated mean retrieved SSS, and standard deviation difference maps for the Aquarius 5.6 second samples. Right panels show the zonal average simulated retrieval difference standard deviation, mean difference and SST. The 30-day mean retrieval accurately portrays the input field. The zonal averages of the mean difference show very small residuals over most latitudes, and apparent systematic errors increasing toward the higher northern latitudes to $0.2 p s s$. In general, the standard deviations show lower errors in tropical to mid latitudes (warmer SST) and increasing error toward the poles (colder SST) as would be predicted from the emissivity model (Fig. 1). The global standard deviation for 5.6 second samples and land fraction $<0.1 \%$ is $\sim 0.15$ pss in the mid latitudes (SST>10C) and 0.22 pss for all SSTs.

Differences between matched satellite and in situ measurements are attributed to several factors. 1) The mis-calibration of either the satellite or in situ sensor; where it is assumed that the latter is generally the more accurate. 2) The salinity offset between the top $\sim 1-2 \mathrm{~cm}$ sensed radiometrically by the satellite and depth of the in situ sample, or skin effect, can be significant at or near times of strong precipitation or evaporation. 3) The difference between a point measurement and the large area integrated by the satellite footprint will be a factor in areas of large spatial gradients such as fronts and eddies. 4) The salinity difference between the in situ sample and the center, or bore sight, location of the satellite footprint and/or time difference of the satellite pass must also be taken into account. The existing in situ observing system is already providing data to address these problems, although there are some enhancements that will be required.

Presently, the observing network provides globally distributed sampling of $>3000$ Argo floats, which nominally sample from $2000 \mathrm{~m}$ to the surface $(\sim 5 \mathrm{~m})$ every 10 days [21]. These data are used to interpolate broad scale SSS maps from which climatological trends are observed relative to the WOA historical mean [7]. The Argo array will be the primary data resource for satellite salinity cal/val because of the large number of spatially distributed samples it regularly provides. The capability to fit and remove long-baseline (one/orbit) and basin-scale biases will be particularly useful. Argo salinity sensors are generally disabled at depths shallower than $5 \mathrm{~m}$ in order to prevent contamination from surfactants when the sensor breaks the surface. This practice is essential for maintaining the long-term calibration stability of the sensor. However, using these data to calibrate satellite SSS may introduce biases when there are significant vertical gradients near the surface, which is more likely in heavy precipitation zones [22]. Experiments are underway on about 20 test buoys using a supplemental surface temperature salinity (STS) sensor to profile from about $30 \mathrm{~m}$ to the surface with a vertical resolution of about $10 \mathrm{~cm}$ [23]. These are 
presently being deployed at various sites to gather statistics on the magnitude and statistics of the $0-5 \mathrm{~m}$ salinity differences and near surface salinity gradients.

The numerous fixed ocean mooring sites (TAO/TRITON, PIRATA, RAMA and climate reference sites; [24] are contributing significantly to our understanding of SSS temporal variability from diurnal to decadal time scales [25], [26] and [27]. These mooring arrays have been outfitted with salinity sensors over the past several years, with sensors generally mounted at $\sim 1 \mathrm{~m}$ depth. In addition to their direct comparisons for satellite cal/val, the mooring time series define the interannual variability (Fig. 1), decorrelation time scales and diurnal cycle [28] which is particularly important to evaluating the measurement uncertainties due to diurnal aliasing from sun-synchronous satellites.

Thermosalinograph (TSG) sensors mounted on ships provide another key part of the observing system. The western tropical Pacific data set, including bucket samples that preceded TSGs, is perhaps the most extensive and longest duration regional SSS record. This has been the basis of several studies of the seasonal to decadal SSS variability in the region and its relation to ENSO, surface advection and rainfall (e.g [25], [26] and [27]). This record was used to evaluate the SSS sampling requirements to resolve regional climate variability scales for OceanObs99 [6]. The alongtrackship data also help understand the spatial variability for satellite cal/val. Figure 5, for example, contains a comprehensive map of ship tracks that shows the rms difference (color scale) between point SSS measurements before and after an along track $150 \mathrm{~km}$ wide Gaussian filter. This represents the portion of the rms difference between satellite and in situ point measurements that can be attributed to the averaging effect of a $150 \mathrm{~km}$ satellite footprint. These results indicate that this term is likely to be $<0.1 \mathrm{pss}$, except in strong frontal regions such as the Gulf Stream. Another important spatial term is the expected SSS difference from the spacing between the in situ location and the bore sight (center) of the satellite footprint. Figure 5 shows the rms SSS difference between shipboard TSG measurements as a function of their along track separation distance, composited using the ensemble data set. Curves are shown for unfiltered differences, and differences between filtered and unfiltered data. The results indicate that the effect of spatial averaging is less important that the separation distance, and that the rms SSS differences commonly exceed 0.2 pss for separation distances of $>75 \mathrm{~km}$. This information guides criteria for screening in situ data for cal/val purposes based on the distance from the bore sight.

The Global Drifter Program (GDP) surface velocity drifter array [29] can be used to deploy a large number of SSS sensors. A successful experiment in the western tropical Pacific $\sim 1994$ with sensors at $\sim 11 \mathrm{~m}$ depth showed very good stability over $\sim 300$ days. Results in other areas have been mixed, with the key problem being the rapidly degrading conductivity calibration caused by biofouling. These technical issues have largely been overcome, with recent experiments in the Bay of Biscay resulting in calibration drifts $<0.06 \mathrm{psu}$ over a nine month period [30]. Sensors in these newer tested configurations are mounted at less than $1 \mathrm{~m}$ depth. Drifters generally have $>1$ year longevity and typically transit $>1000 \mathrm{~km}$ during their life cycle. As Lagrangian platforms, they measure both temporal and spatial variability. Drifters can provide data from the many remote regions not frequented by ships equipped with TSGs. They are continuously sampling at the surface and thus provide simultaneous measurement during a satellite overpass. (This is in contrast to Argo, which surfaces once every 10 days and thus requires an uncertainty be added for the temporal offset.)

\section{PROPOSED ENHANCEMENTS TO THE IN SITU SSS OBSERVING SYSTEM}

Presently, the highest priorities are to enhance the SSS measurement capability on Argo and GDP drifters. In addition to the satellite cal/val issues described here, these enhancements will aid studies of the mixed layer dynamics and understanding the vertical processes that partially balance the net surface water flux. Figure 5 illustrates the recent global distribution status of both the Argo and GDP arrays. The shaded areas denote regions where enhanced SSS measurement capability is recommended for each respective platform (STS for Argo and adding SSS sensors to GDP drifters). Some of these are already planned. For the remainder, these are preliminary options, open to further discussion, for systems for which funding is established or likely, but deployment strategies are not yet resolved. In addition to these, additional resources may come available as part of one or more regional process experiments now in preliminary planning to occur during the satellite missions

\subsection{Argo with STS}

The purpose of the STS on Argo is to document the skin effect for SSS remote sensing and measure near surface stratification, which are related to mixing and surface buoyancy flux. The shaded areas emphasize strong surface fluxes in the North Atlantic subtropical gyre, northeast Pacific, tropical Pacific and northern Indian Ocean. These are candidate regions where differences between evaporation and precipitation (E-P) are at their extremes, either plus or minus, making them key for validating satellite SSS and studying the upper ocean physical processes that govern SSS. As seen in Fig. 1, the northeast Pacific and the subtropical Atlantic encompass the minima and maxima of the open ocean SSS, as does the northern Indian Ocean on either side of 
the Indian subcontinent, whereas the tropical Pacific covers the middle of the range. When calibrating a technical instrument such as a satellite SSS sensor, it is good practice to obtain adequate data at both ends of the measurement range. There are other oceanographic considerations as well. The northeast Pacific surface circulation is divergent, favoring Argo to have a longer residence time than surface drifters. The tropical Pacific is key because of the greater likelihood of the skin effect from excess precipitation, and the important research problems on the influences that rainfall, barrier layers and SSS variability have on ENSO dynamics. In the subtropical Atlantic, the respective roles of the excess evaporation, circulation and mixing on maintaining the salt-freshwater balance in this SSS maximum is likely to be a research focus during the satellite missions. A suggested deployment strategy of 100 STS-Argo floats is indicated in Tab. 2. Funds are now secured from NASA for 70 STS floats, with about a dozen already deployed in the tropical Pacific and North Indian Oceans.
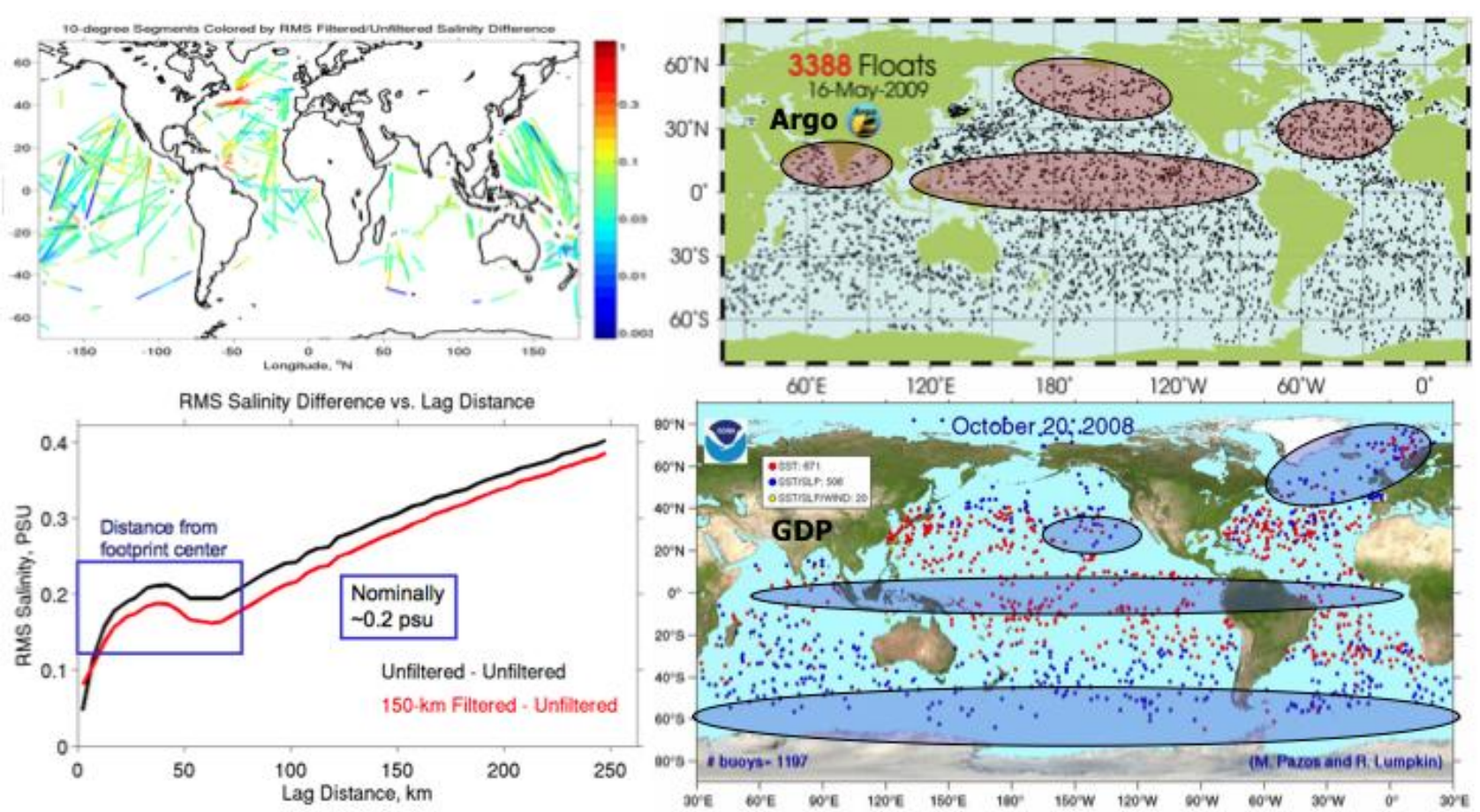

Figure 5: Left top panel: Map of ship tracks used to analyze SSS spatial variability. The color scale shows the rms difference between point measurements before and after an alongtrack $150 \mathrm{~km}$ wide Gaussian filter was applied to assess the smoothing effect of the Aquarius satellite footprint. Left bottom panel: The rms SSS difference along track as function of distance, differencing each point measurement with unfiltered (black) and 150km filtered (red) alongtrack data. Right panels: Recent deployment status maps for the Argo (upper) and GDP (lower) arrays, showing their nominal global sampling distributions. The shaded areas denote regions for enhancing the array with STS sensors on Argo and SSS sensors on GDP drifters, respectively, as described in the text and Tab. 2. 



\subsection{GDP drifters with SSS}

Adding SSS to GDP drifters will provide continuous surface measurements in a water-following frame and autonomous access to remote regions, particularly the high latitudes. The suggested priority for GDP-SSS deployment is the Southern Ocean, the northern Atlantic and the Nordic Seas, and the equatorial oceans (Fig. 5). The high latitudes are known to be important deepwater formation regions where surface density is most sensitive to SSS variability. The satellite SSS measurement uncertainty is also the largest in these zones. (Figure 4), highlighting the need for sufficient in situ data for satellite cal/val and to ensure the optimal SSS resolution and accuracy from the combined analysis of both in situ and satellite data. In the equatorial oceans, SSS is known to vary rapidly because of frequent occurrence of rain and/or proximity of large river discharges, and is a common region for barrier layer formation. Figure 5 also shows a secondary GDPSSS region in the subtropical Pacific where the surface circulation forms a large convergence zone [29]. A collection of drifters will tend to have long residence times in the region and provide well-sampled reference sites. The purpose is to provide another regional site to monitor satellite calibration over time, assuming the North Atlantic is suitably covered by Argo-STS. Alternative subtropical convergence zones would be suitable such as the South Pacific or South Atlantic. The present European deployment strategy in preparation for SMOS includes the following: (a) The GLOSCAL (GLobal Ocean Surface salinity CALibration and validation) French project will deploy 30 drifters in North Atlantic, equatorial Atlantic and equatorial Pacific, with about 10 in each region, (b) the German group will deploy 25 in polar seas and equatorial Pacific, and (c) the Spanish group will deploy 40 in the subtropical Atlantic, Southern Ocean and, possibly some in the Mediterranean Sea, with the precise distribution still to be determined. This provides approximately 95 drifters. In the US, as many as 55 drifters are being proposed for deployment beginning in 2011, within the approximate regions indicated in Tab. 2.

\begin{tabular}{|c|c|c|c|c|}
\hline \multirow[t]{3}{*}{ Platform } & \multirow[t]{3}{*}{ Regions } & \multicolumn{3}{|c|}{ Number of buoys } \\
\hline & & \multirow[t]{2}{*}{ Suggested } & \multicolumn{2}{|c|}{ Planned } \\
\hline & & & Europe & US \\
\hline \multirow[t]{5}{*}{ Argo-STS } & Subtropical N. Atlantic & 24 & & 24 \\
\hline & Tropical Pacific & 50 & & 30 \\
\hline & Northeast Pacific & 20 & & 10 \\
\hline & North Indian Ocean & 6 & & 6 \\
\hline & Subtotals & 100 & & 70 \\
\hline \multirow[t]{6}{*}{ GDP-SSS } & Southern Ocean & 80 & 10 & 40 \\
\hline & Equatorial Pacific & 20 & 30 & \\
\hline & Equatorial Atlantic/Indian & 20 & 20 & \\
\hline & Nordic Seas & 60 & 15 & 15 \\
\hline & Subtropical N. Atlantic & 20 & 20 & \\
\hline & Subtotals & 200 & 95 & 55 \\
\hline
\end{tabular}

\section{CONCLUSIONS - THE WAY FORWARD}

The complementary nature of the expanded in situ network and new satellite observing systems will result in more highly resolved and accurate SSS fields than have been possible before. Such a capability will put SSS on a par with global sea surface temperature (SST) data sets that have been available for several decades. The new SSS information will serve several needs for ocean and climate research, such as: a) filling the SSS observational void in the Southern Ocean, b) diagnostic analyses linking SSS variability to other key climate indices, c) reducing the uncertainty in the marine freshwater and heat budgets, d) studying upper ocean mixing and advection, e) improving the initialization and fidelity of coupled climate models, to name a few. Recommended enhancements for adding near-surface profiling to Argo (Argo-STS) and salinity sensors to GDP drifters (GDP-SSS) will both improve satellite $\mathrm{cal} / \mathrm{val}$ and our understanding of the relevant upper ocean physics. These enhancements should continue as an integral part of the sustained observing system. As the modeling capability to simulate salinity improves, the research community will produce a routine synthesis of the global salinity assimilating both in situ and satellite salinity measurements as well as other complementary observations.

The future prospects for sustained satellite salinity measurements are less clear. SMOS and Aquarius are explorer-type missions with expected lifetimes $\sim 3-5$ years (but like many such missions, may operate much longer). ESA is considering a SMOS follow-on for operational measurements. In the US, NASA is developing the Soil Moisture Mapping mission (SMAP) which can provide follow SSS measurements, but with a very different design that will perhaps not have the same accuracy as Aquarius. Much will be learned from the SMOS and Aquarius missions that will guide the space agencies on the strategy to maintain an on-going satellite-based salinity measurement program for climate observations. It is recommended that the space agencies begin formulating these plans now.

\section{REFERENCES}

1. US CLIVAR Salinity Working Group (2007). Report of the US CLIVAR Salinity Working Group. US CLIVAR Report no. 2007-1. US CLIVAR Office, Washington, DC. Available online at: http://www.usclivar.org/Pubs/Salinity_final_report.pdf

2. Cravatte S., T. Delcroix, D. Zhang, M. McPhaden, and J. Leloup, (2009). Observed freshening and warming of the western Pacific warm pool. Clim. Dyn., 33:565-589, doi:10.1007/s00382-009-0526-7.

3. Gordon, A.L. and C.F. Giulivi, (2008). Sea Surface Salinity trends over 50 years within the Subtropical North Atlantic. Oceanography, 21, 20-29. 
4. Boyer, T.P., S. Levitus, J.I. Antonov, R.A. Locarnini, and H.E. Garcia (2005). Linear trends in salinity for the World Ocean, 1955-1998, Geophysical Research Letters 32, doi:10.1029/2004GL021791.

5. Antonov, J. I., R. A. Locarnini, T. P. Boyer, A. V. Mishonov, and H. E. Garcia (2006). World Ocean Atlas 2005, Volume 2: Salinity. S. Levitus, Ed. NOAA Atlas NESDIS 62, U.S. Government Printing Office, Washington, D.C., $182 \mathrm{pp}$.

6. Lagerloef, G. and T. Delcroix (2001). Sea surface salinity; a regional case study for the tropical Pacific Observing the Oceans in the 21st Century; a strategy for global observations. C. Koblinsky and N. Smith, Eds., GODAE Project Office, Bureau of Meteorology, Melbourne, Australia. 604 pp.

7. Riser, S., L. Ren, and A. Wong (2008). Salinity in Argo: a modern view of a changing ocean. Oceanography, 20: 56-67.

8. Johnson, G.C., and J.M. Lyman (2008). Global oceans: Sea surface salinity. In State of the Climate in 2007, D.H. Levinson and J.H. Lawrimore, eds., Bull. Amer. Meteor. Soc. 89:S45-S47.

9. Klein, L.A. and C.T. Swift (1977). An improved model for the dielectric constant of sea water at microwave frequencies, IEEE Trans. Antennas and Propag., AP-25, 104-111.

10. Meissner, T. and F. J. Wentz (2003). The complex dielectric constant of pure and sea water from microwave satellite observations, IEEE Trans. Geosci. Remote Sens., vol. 42, pp. 1836-1849.

11. Swift, C.T. and R.E. McIntosh (1983). Considerations for microwave remote sensing of ocean surface salinity, IEEE Trans. Geosci. Rem. Sens., GE-21, 480-491.

12. Reul, N., S. Saux-Picart, B. Chapron, D. Vandemark, J. Tournadre, and J. Salisbury (2009). Demonstration of ocean surface salinity microwave measurements from space using AMSR-E data over the Amazon plume, Geophys. Res. Lett.

13. Font, J,. G.S.E. Lagerloef, D.M. Le Vine, A. Camps, O.Z. Zanife (2004). The Determination of Surface Salinity with the European SMOS Space Mission, IEEE Trans. Geosci. Rem. Sens., 42, 2196-2205.

14. Zine, S., J. Boutin, J. Font, N. Reul, P. Waldteufel, C. Gabarro, J. Tenerelli, F. Petitcolin, J. L. Vergely, and M. Talone (2008). Overview of the SMOS Sea Surface Salinity Prototype Processor. IEEE Transactions on Geoscience and Remote Sensing, 621 - 645, doi:10.1109/TGRS.2008.915543.

15. Sabia et al., (2006). Impact on Sea Surface Salinity Retrieval of Different Auxiliary Data Within the SMOS Mission, IEEE Trans. Geosci. Rem. Sens., 44, 2769-2777.

16. Gabarro, C., M. Portabella, M. Talone and J. Font (2009). Towards an Optimal SMOS Ocean Salinity Inversion Algorithm, IEEE Trans. Geosci. Rem. Sens, Vol. 6, \# 3, 509-613, doi:10.1109/LGRS.2009.2018490.
17. Lagerloef, G., F. Colomb, D. LeVine, F. Wentz, S. Yueh, C. Ruf, J. Lilly, J. Gunn, Y. Chao, A. deCharon, G. Feldman, and C. Swift (2008). The Aquarius/SAC-D mission: designed to meet the salinity remote-sensing challenge. Oceanography, 20: 68-81.

18. Le Vine, D. M., G. S. E. Lagerloef, R. Colomb, S. Yueh, and F. Pellerano (2007). Aquarius: An Instrument to Monitor Sea Surface Salinity from Space, IEEE Trans. Geosci. Remote Sens., vol. 45, pp. 2040-2050.

19. Kim SB, Wentz F, LeVine D, Lagerloef GSE (2010) Simulation of sea surface salinity retrieval with the Aquarius L-band radiometer. IEEE Trans Geosci Rem Sens (in press).

20. Yueh, S.H., R. West, W.J. Wilson, F.K. Li, E.G. Njoku, and Y. Rahmat-Samii, (2001). Error sources and feasibility for microwave remote sensing of ocean surface salinity”, IEEE Trans. Geosci. and Remote Sensing, Vol 39 , \#5, pp 1049-1059.

21. Freeland, H. \& Co-Authors (2010)."Argo - A Decade of Progress" in these proceedings (Vol. 2), doi:10.5270/OceanObs09.cwp.32.

22. Henocq, C., J. Boutin, F. Petitcolin, G. Reverdin, S. Arnault, and P. Lattes, 2010: Vertical Variability of NearSurface Salinity in the Tropics: Consequences for L-Band Radiometer Calibration and Validation. Journal of Atmospheric and Oceanic Technology, 27, 192-209.

23. S. Riser (2009), personal communication.

24. McPhaden, M. \& Co-Authors (2010). "The Global Tropical Moored Buoy Array" in these proceedings (Vol. 2), doi:10.5270/OceanObs09.cwp.61.

25. Delcroix, T., and M. J. McPhaden (2002). Interannual sea surface salinity and temperature changes in the western Pacific warm pool during 1992-2000, J. Geophys. Res., 107(C12), 8002, doi:10.1029/2001JC000862.

26. Delcroix, T., M. J. McPhaden, A. Dessier, and Y. Gouriou (2005). Time and space scales for sea surface salinity in the tropical oceans, Deep Sea Res., Part I, 52(5), 787813. doi:10.1016/j.dsr.2004.11.012

27. Delcroix, T., S. Cravatte, and M. J. McPhaden (2007). Decadal variations and trends in tropical Pacific sea surface salinity since 1970, J. Geophys. Res., 112, C03012, doi:10.1029/2006JC003801.

28. Cronin, M., and M. McPhaden (1998). Upper ocean salinity balance in the western equatorial Pacific, $J$. Geophys. Res., 103, 27,567 - 27,587.

29. Dohan, K. \& Co-Authors (2010). "Measuring the Global Ocean Surface Circulation with Satellite and In Situ Observations" in these proceedings (Vol. 2), doi:10.5270/OceanObs09.cwp.23.

30. Reverdin, G., P. Blouch, J. Boutin, P. P. Niiler, J. Rolland, W. Scuba, A. Lourenco, and A. F. Rios (2007). Surface Salinity Measurements - COSMOS 2005 Experiment in the Bay of Biscay, J. Atm. Ocean. Techn., 24, pp. 1643 1654. doi:10.1175/JTECH2079.1. 